\title{
Asarone and Metformin Modulates the Oxidant- Antioxidant Imbalance on Experimentally Induced Hepatocellular Carcinoma during Diabetic Condition
}

\author{
Bhrigu Kumar Das ${ }^{1,2}$, Pramod Channabasappa Gadad ${ }^{1,2, *}$ \\ 1'Department of Pharmacology, KLE College of Pharmacy (A Constituent Unit of KLE Academy of Higher Education and Research, \\ Belagavi), Vidyanagar, Hubballi, Karnataka, INDIA. \\ ${ }^{2}$ Off-campus Basic and Applied Sciences Research Centre of KLE Academy of Higher Education and Research at KLE College of \\ Pharmacy, Vidyanagar, Hubballi, Karnataka, INDIA.
}

\begin{abstract}
Aim: The aim of the present study was planned to investigate the efficacy of asarone and metformin $\mathrm{HCl}$ as an antioxidant on experimentally induced diabetic-hepatocellular carcinoma (HCC) condition in male Wistar rats. Methods: Diabetes was induced in experimental rats by single intraperitoneal injection of streptozotocin (STZ; $55 \mathrm{mg} / \mathrm{kg}$ b.w.). Following two weeks of STZ injection, the diabetic-HCC condition was simulated in the rats with a single intraperitoneal dose of diethylnitrosamine (DEN; $200 \mathrm{mg} /$ $\mathrm{kg}$ b.w.). The $\alpha$-and $\beta$-asarone combination in the ratio of $1: 1(50 \mu \mathrm{g} / \mathrm{kg} \mathrm{b.w.)}$ and metformin $\mathrm{HCl}(250 \mathrm{mg} / \mathrm{kg}$ b.w.) treatment were orally given to the diabetic-HCC rats up to 18-weeks. At the end of the experimental period, rats were sacrificed after the withdrawal of blood for biochemical and liver samples were isolated for the antioxidant and histopathological analysis. Results: The elevated levels of liver function test such as alkaline phosphatase, bilirubin and decreased levels of total protein, albumin and globulin indicated the hepatic damage in the diabetic-HCC rats. Further, the STZ + DEN-induced oxidative stress was confirmed by the elevated levels of lipid peroxidation (LPO) and decreased levels of superoxide dismutase (SOD), catalase (CAT), glutathione peroxidase $(G P x)$, reduced glutathione (GSH) and Vitamin-C. Treatment with asarone and metformin significantly ameliorated the STZ + DEN-induced hepatic damage and oxidative stress. Histopathological evidence also showed recovery of the hepatic architecture in diabetic$\mathrm{HCC}$ rats treated with asarone and metformin. Conclusion: Asarone and metformin exhibit good hepatoprotective and antioxidant potential against STZ + DEN-induced HCC in rats.
\end{abstract}

Key words: Asarone, Diethylnitrosamine, Metformin, Oxidative stress, Streptozotocin.

\section{INTRODUCTION}

Diabetes is the result of chronic hyperglycaemia, the most prevalent metabolic syndrome categorized by defective secretion and/or action develops due to the imbalance in carbohydrate, protein and fat metabolism. ${ }^{1}$ The chronic increase in the glucose level has undesirable effects on numerous tissues or organs, namely kidneys, liver, muscles, adipose tissues and pancreas henceforth promoting the complications of early diabetes. ${ }^{2}$ Further, a large number of epidemiological reports from Asia, North America and
Europe strongly associate diabetes with the elevated risk of incidence and growth of hepatocellular carcinoma (HCC). ${ }^{3,4}$ Studies have shown that oxidative stress plays a central role and also shared as causal factors thereby correlating with the instigation and development of HCC during diabetic condition. ${ }^{5,6}$

During oxidative stress, the generation of free radical and their elimination disturb the equilibrium along with its cellular integrity and as a result, it leads to cytotoxicity, damage of DNA, protein degradation
Submission Date: 04-05-2020; Revision Date: 14-07-2020; Accepted Date: 09-09-2020

DOI: 10.5530/ijper.54.4.198 Correspondence: Dr. Pramod C Gadad Department of Pharmacology, KLE College of Pharmacy (A Constituent Unit of KLE Academy of Higher Education and Research, Belagavi), Vidyanagar, Hubballi 580031 , Karnataka, INDIA.

Phone no: +91 8362373174 Email id: gadadpramod@ gmail.com

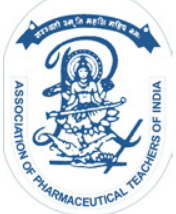

www.ijper.org 
and carcinogenicity. ${ }^{5-7}$ Here, the antioxidant defence mechanisms protect the cells against the reactive oxygen species (ROS) and therefore the use of antioxidants would restore or protect against hepatic impairment relating oxidative stress. ${ }^{5}$

There are epidemiological, clinical and experimental reports suggesting that metformin $\mathrm{HCl}$, a biguanide class of antidiabetic drug decreases the risk of incidence of cancer with diabetes. ${ }^{8}, 9$ This reduction in the severity of cancer might be due to decreased cell proliferation, cell cycle arrest, reduced insulin-like growth factor, apoptosis and inhibition of angiogenesis which are connected with both the regulation of $5^{\prime}$ adenosine monophosphate-activated protein kinase (AMPK)dependent and independent signalling pathway. ${ }^{8,10}$ On the other hand, $\alpha$-and $\beta$-asarone, the two major active constituents in volatile oils of Acorus calamus along with its extract showed cytotoxic as well as antidiabetic effects. ${ }^{11-13}$

Our earlier study reported that asarone treatment decreased the development of HCC in a hyperglycaemic condition comparable to metformin. ${ }^{14}$ Considering the above fact that the altered cellular oxidative stress is responsible and also shared as a causal factor between both the diseases, however, there is no evidence related to asarone to support their protection against oxidative stress-induced damage in diabetic-HCC condition. Therefore, the present investigation evaluated the efficacy of asarone and metformin $\mathrm{HCl}$ in maintaining the balance in the oxidant-antioxidant status during the diabetic-HCC condition in male Wistar rats.

\section{MATERIALS AND METHODS}

\section{Experimental animals}

Healthy male Albino Wistar rats five-month-old weighing from 150-200 $\mathrm{g}$ were used for this study. They were housed and maintained at $27 \pm 2^{\circ} \mathrm{C}$ with $12 \mathrm{~h}$ light and dark cycle. Animals were provided with standard pelleted diet and water ad libitum. All animal experiments were achieved in agreement with the guidelines after needed approval by the Institutional Animal Ethical Committee (Approval no. 07/ KLEU'SCOPH/16).

\section{Chemicals}

Streptozotocin (STZ) extra pure was obtained from Sisco-Research Laboratories (SRL) Pvt. Ltd., Mumbai, India. Diethylnitrosamine (DEN), $\alpha$-and $\beta$-asarone were procured from Sigma-Aldrich Chemical Company (USA). Metformin $\mathrm{HCl}$ was obtained as gratis from Angels Pharma India Pvt. Ltd., Hyderabad, India. All the other reagents and chemicals were analytically graded and procured from standard commercial suppliers.

\section{Experimental induction of diabetes and hepatocellular carcinoma (HCC)}

The animals were made diabetic with a single intraperitoneal dose of freshly prepared solution of streptozotocin (STZ; $55 \mathrm{mg} / \mathrm{kg}$ b.w.) in overnight fasted rats. The ice-cold citrate buffer solution $(0.05 \mathrm{M} ; \mathrm{pH}$ 4.5) was used for the preparation of STZ. After the injection of STZ, the rats were supplied with sucrose (prepared as $10 \% \mathrm{w} / \mathrm{v}$ water solution) for the next $24 \mathrm{~h}$ to prevent fatal hypoglycaemia. The HCC was induced with the help of a single intraperitoneal dose of carcinogenic agent diethylnitrosamine (DEN; $200 \mathrm{mg}$ / $\mathrm{kg}$ b.w.) prepared in $\mathrm{NaCl}$ solution $(0.9 \% \mathrm{w} / \mathrm{v}) .{ }^{14}$

\section{Experimental protocol}

The animals were randomly divided into five (5) groups $(n=8)$, except one rat each from group II and IV and two rats from group III died before the end of the study as tabulated in Table 1. Following 18-weeks of study, blood was collected from the overnight fasted rats for serum separation under mild ether anaesthesia. The liver tissues were collected from the euthanized rats for evaluation of different parameters.

\begin{tabular}{|c|c|}
\hline Groupings & Treatment \\
\hline I & Normal control (NC); received intraperitoneal injection of $0.9 \% \mathrm{w} / \mathrm{v} \mathrm{NaCl}$ solution ( $1 \mathrm{ml} / \mathrm{kg} \mathrm{b.w.).}$ \\
\hline II & Diabetogenic (STZ); received a single dose of streptozotocin (STZ). \\
\hline III & $\begin{array}{l}\text { Diabetic-hepatocellular carcinoma (STZ+DEN); following two weeks of STZ-injection and after confirmation of increased } \\
\text { glucose levels, this group received a single injection of diethylnitrosamine (DEN) to simulate diabetic-HCC condition. }\end{array}$ \\
\hline IV & $\begin{array}{l}\text { Treatment (STZ+DEN+Asarone); following two weeks of STZ +DEN-injections, this group received a mixture dose of } \\
\text { alpha-and beta-asarone }(50 \mu \mathrm{g} / \mathrm{kg} \text { b.w.) in the ratio of } 1: 1 \text {. The asarone was administered orally for five days per week till } \\
\text { the end of the study after preparing in } 0.5 \% \mathrm{w} / \mathrm{v} \text { sodium carboxymethyl cellulose solution. }{ }^{14}\end{array}$ \\
\hline $\mathrm{V}$ & $\begin{array}{c}\text { Treatment (STZ+DEN+Metformin HCl); alike to group IV except that the test compound metformin } \mathrm{HCl}(250 \mathrm{mg} / \mathrm{kg} \mathrm{b.w.}) \text {, } \\
\text { which was freshly prepared in distilled water substituted the asarone. }{ }^{14}\end{array}$ \\
\hline
\end{tabular}




\section{Preparation of liver tissue homogenates}

The excised liver tissues from all the experimental groups were rinsed with physiological $\mathrm{NaCl}$ solution $(0.9 \% \mathrm{w} / \mathrm{v})$ and further one portion was used for the preparation of tissue homogenate $(10 \% \mathrm{w} / \mathrm{v})$ in 0.15 $\mathrm{M}$ Tris- $\mathrm{HCl}$ buffer solution of $\mathrm{pH}$ 7.4. Subsequently, it was centrifuged $\left(10,000 \times \mathrm{g} ; 4^{\circ} \mathrm{C}\right.$ for $\left.10 \mathrm{~min}\right)$ and the clear supernatant obtained was taken for further studies.

\section{Estimation of hepatic damage}

The study of liver function parameters such as alkaline phosphatase, bilirubin, total protein and albumin were measured with the help of commercially available kit using Erba Chem 7 semi-automated analyser obtained from Erba Transasia Bio-Medicals Ltd., India.

\section{Measurement of STZ+DEN-mediated oxidative stress markers}

The enzymatic antioxidants namely superoxide dismutase (SOD) were examined according to the method of Kakkar et al. ${ }^{15}$ catalase (CAT) according to the method of Sinha AK, ${ }^{16}$ lipid peroxidation (LPO) according to the methods of Niehaus et al. Jiang et al. and Ohkawa et al. ${ }^{17-19}$ and glutathione peroxidase (GPx) as described by Rotruck et al. ${ }^{20}$ in the liver tissue homogenate for all the experimental groups. The nonenzymatic antioxidants namely reduced glutathione (GSH) were carried out as described by Ellman GL ${ }^{21}$ and Vitamin-C according to the method of Omaye $e t$ $a .^{22}$

\section{Histological study of liver tissue (H and E)}

The formalin-fixed liver tissues were dehydrated with 60 to $100 \%$ isopropyl alcohol solution and fixed in paraffin wax. For the histology study, liver section slides stained with haematoxylin-eosin ( $\mathrm{H}$ and $\mathrm{E}$ ) were captured with a light microscope (Olympus Microsystem, ModelCKX41, Japan).

\section{Statistical analysis}

The obtained data from the various experimental groups were expressed as mean \pm SEM using statistical software package 'GraphPad Prism version 6.0'. The results were analysed using a one-way ANOVA test. Further, Bonferroni multiple comparison test was followed considering $p$ values of $<0.05$ as significant.

\section{RESULTS}

\section{Effect of asarone and metformin against STZ+DEN- induced hepatic damage}

The effect of asarone and metformin on the levels of liver function parameters are illustrated in Table 2. The pathophysiological indices in the STZ alone and STZ+DEN administered rats showed a significant increase $(P<0.001)$ in the levels of ALP, TB and DB along with a decrease in total protein, albumin and globulin levels compared to the normal group. Further, the treated groups significantly overcame the deleterious effects in comparison to STZ+DEN group.

\section{Effect of asarone and metformin on oxidative stress markers}

The alterations in the levels of enzymatic and nonenzymatic antioxidants in the hepatic tissues for all the experimental groups are shown in Table 3. Animals administered with STZ alone and STZ+DEN rats showed a significant increase in the levels of LPO along with a decrease in the levels of SOD, CAT, GPx, GSH and Vitamin-C compared to the normal group. The treatment groups (asarone and metformin) significantly restored the levels of enzymic and non-enzymic antioxidants to normal compared to STZ+DEN group.

\section{Histopathological features of liver tissue}

The typical histopathological features of rat livers for all the groups by haematoxylin-eosin (H\&E) staining are represented in Figure 1. The STZ-treated livers at the

Table 2: Effect of asarone and metformin on hepatic serum markers of different experimental groups.

\begin{tabular}{|c|c|c|c|c|c|}
\hline Parameters/Group & $\begin{array}{c}\text { I } \\
\text { (NC) }\end{array}$ & $\begin{array}{c}\text { II } \\
\text { (STZ) }\end{array}$ & $\begin{array}{c}\text { III } \\
\text { (STZ+DEN) }\end{array}$ & $\begin{array}{c}\text { IV } \\
(\mathrm{STZ}+\mathrm{DEN}+\text { Asarone) }\end{array}$ & $\begin{array}{c}\text { V } \\
(\mathrm{STZ}+\mathrm{DEN}+\text { Metformin) }\end{array}$ \\
\hline ALP (IU/L) & $93.09 \pm 0.91$ & $164.80 \pm 2.24^{* * *}$ & $263.70 \pm 3.33^{* * *}$ & $128.70 \pm 2.11^{* * *}, a$ & $110.20 \pm 5.33^{* *}, a$ \\
\hline TB (mg/dl) & $0.33 \pm 0.01$ & $0.58 \pm 0.01^{* * *}$ & $1.07 \pm 0.04^{* * *}$ & $0.39 \pm 0.04^{a}$ & $0.35 \pm 0.02^{\mathrm{a}}$ \\
\hline $\mathrm{DB}(\mathrm{mg} / \mathrm{dl})$ & $0.07 \pm 0.006$ & $0.27 \pm 0.01^{\text {t*t*}}$ & $0.97 \pm 0.02^{* * *}$ & $0.35 \pm 0.01^{* * *}, \mathrm{a}$ & $0.14 \pm 0.01^{*}, \mathrm{a}$ \\
\hline Total protein $(\mathrm{mg} / \mathrm{dl})$ & $8.84 \pm 0.19$ & $7.18 \pm 0.06^{* * *}$ & $4.76 \pm 0.17^{* * * *}$ & $6.32 \pm 0.16^{* * *}, a$ & $7.20 \pm 0.08^{* * *}, \mathrm{a}$ \\
\hline Albumin (mg/dl) & $5.63 \pm 0.16$ & $4.22 \pm 0.27^{* * *}$ & $2.14 \pm 0.14^{* * *}$ & $4.09 \pm 0.04^{* * *}, a$ & $4.57 \pm 0.12^{* * *}, a$ \\
\hline Globulin (mg/dl) & $3.33 \pm 0.06$ & $2.87 \pm 0.11$ & $2.27 \pm 0.14^{t * *}$ & $2.86 \pm 0.11^{\mathrm{c}}$ & $3.00 \pm 0.13^{b}$ \\
\hline
\end{tabular}

Values expressed as mean \pm SEM. ${ }^{*} P<0.05,{ }^{* *} P<0.01,{ }^{* * * *} P<0.001$ Vs normal group and ${ }^{c} P<0.05,{ }^{b} P<0.01,{ }^{a} P<0.001$ Vs STZ+DEN group.

$\mathrm{NC}=$ Normal control, $\mathrm{STZ}=$ Streptozotocin, DEN=Diethylnitrosamine, ALP=Alkaline phosphatase, $\mathrm{TB}=$ Total bilirubin, $\mathrm{DB}=\mathrm{Direct}$ bilirubin. 


\begin{tabular}{|c|c|c|c|c|c|}
\hline Parameters/Group & $\begin{array}{c}\text { I } \\
\text { (NC) }\end{array}$ & $\begin{array}{c}\text { II } \\
\text { (STZ) }\end{array}$ & $\begin{array}{c}\text { III } \\
\text { (STZ+DEN) }\end{array}$ & $\begin{array}{c}\text { IV } \\
\text { (STZ+DEN+Asarone) }\end{array}$ & $\begin{array}{c}\text { V } \\
\text { (STZ+DEN+Metformin) }\end{array}$ \\
\hline SOD (units/min/mg protein) & $8.11 \pm 0.05$ & $4.05 \pm 0.07^{* * *}$ & $3.85 \pm 0.24^{*+*}$ & $6.21 \pm 0.14^{* * * *}, a$ & $6.74 \pm 0.29^{* * *}$, a \\
\hline CAT ( $\mu \mathrm{mol} / \mathrm{min} / \mathrm{mg}$ protein) & $47.38 \pm 1.56$ & $28.79 \pm 1.09^{* * *}$ & $20.39 \pm 0.74^{* * *}$ & $37.71 \pm 1.63^{* * *}, \mathrm{a}$ & $39.55 \pm 0.84^{* * *}, \mathrm{a}$ \\
\hline LPO ( $\mu \mathrm{mol} / \mathrm{min} / \mathrm{mg}$ protein) & $2.49 \pm 0.16$ & $6.22 \pm 0.19^{* * *}$ & $7.55 \pm 0.16^{t * *}$ & $4.70 \pm 0.13^{* * *}, a$ & $3.93 \pm 0.16^{* * *}, a$ \\
\hline GPx ( $\mu \mathrm{mol} / \mathrm{min} / \mathrm{mg}$ protein $)$ & $2.55 \pm 0.12$ & $1.94 \pm 0.10^{* *}$ & $0.99 \pm 0.09^{* * *}$ & $2.03 \pm 0.05^{\star}, \mathrm{a}$ & $2.17 \pm 0.11^{\mathrm{a}}$ \\
\hline GSH ( $\mu g / g$ wet tissue) & $21.17 \pm 0.39$ & $14.17 \pm 0.93^{* * *}$ & $11.19 \pm 0.43^{* * *}$ & $13.89 \pm 0.48^{* * *+c}, c$ & $15.67 \pm 0.19^{* * *}$, a \\
\hline Vitamin-C (mg/g wet tissue) & $0.77 \pm 0.02$ & $0.62 \pm 0.03^{* *}$ & $0.33 \pm 0.02^{+* *}$ & $0.50 \pm 0.03^{* * *}, \mathrm{~b}$ & $0.60 \pm 0.02^{* *}, a$ \\
\hline
\end{tabular}

Values expressed as mean \pm SEM. ${ }^{*} P<0.05,{ }^{* *} P<0.01,{ }^{* * *} P<0.001 \mathrm{Vs}$ normal group and ${ }^{\mathrm{c}} P<0.05,{ }^{\mathrm{b}} P<0.01,{ }^{\mathrm{a}} P<0.001 \mathrm{Vs} S T Z+\mathrm{DEN}$ group. Units are as follows: SOD $=1$ unit of activity equals the enzyme reaction that gave $50 \%$ inhibition of nitro-blue tetrazolium (NBT) reduction in 1 min, $C A T=\mu m o l e s$ of $\mathrm{H}_{2} \mathrm{O}_{2}$ utilized in 1 min, $\mathrm{LPO}=\mu \mathrm{moles}$ of malondialdehyde (MDA) formed in $1 \mathrm{~min}, \mathrm{GPx}=\mu$ moles of glutathione (GSH) oxidized in $1 \mathrm{~min}$

$\mathrm{NC}=$ Normal control, STZ=Streptozotocin, DEN=Diethylnitrosamine, SOD=Superoxide dismutase, CAT=Catalase, LPO=Lipid peroxidation, GPX=Glutathione peroxidase, $\mathrm{GSH}=$ Reduced glutathione.

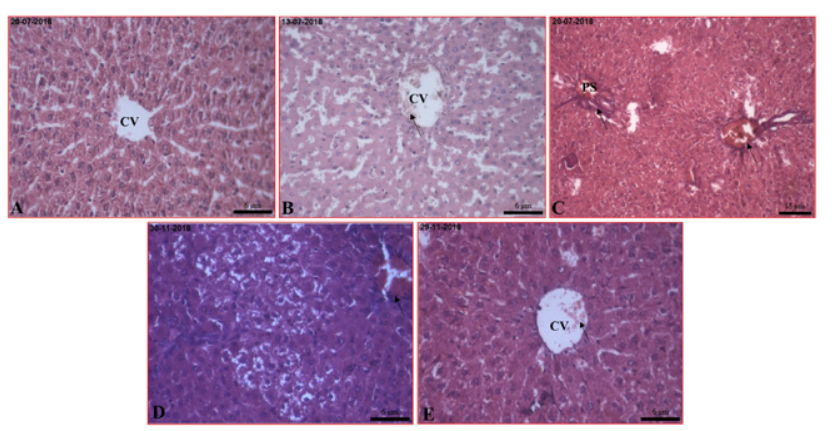

Figure 1: Photomicrographs of haematoxylin-eosin (H and E) stained histological features of liver sections obtained from normal rats (A), STZ-induced diabetic rats (B), STZ+DENinduced diabetic-HCC rats (C), STZ+DEN+Asarone (D) and STZ+DEN+Metformin (E) respectively. Black arrowheads indicate congestion in the central vein $(\mathrm{CV})$ and the portal system (PS). (A, B, D, E, magnification: 200; C, magnification:100). $S T Z=$ Streptozotocin, DEN=Diethylnitrosamine, $\mathrm{CV}=$ Central vein, $\mathrm{PS}=$ Portal system.

end of 18-weeks showed the features of inflammation accompanied by congestion in the sinusoids, central vein (CV) and portal system (PS) in between the hepatocytes compared to normal livers where the hepatic lobules remain intact with well-defined architecture. Whereas, the STZ+DEN-induced diabetic-HCC rats showed structural disorganization of the livers with the development of all the typical features of HCC. Furthermore, following treatment with asarone and metformin, the degree of the toxic effect was reduced through the restoration of the hepatic architecture compared to STZ+DEN group.

\section{DISCUSSION}

This study demonstrates the prophylactic role of asarone and metformin against STZ+DEN-induced hepatic damage and oxidative stress. The effect of STZinstigating hyperglycaemia on the development of HCC following a single injection of DEN in experimental rats unveiled all the characteristic features of diabetes and hepatocarcinogenesis as confirmed in our previous study. ${ }^{14}$

The diabetic liver is strongly correlated with the increased possibility of HCC by 2.5 folds as observed by some studies in contrast with their non-diabetic counterparts. ${ }^{23,24}$ The involvement of the free radicalsmediated oxidative stress during hyperglycaemic condition has been involved in the pathological process and progress of diabetes and it contributes to damage to various tissues and organs, including the liver. ${ }^{25,26}$ The STZ and DEN-induced oxidative stress are responsible for its carcinogenic effects due to the production of reactive oxygen species (ROS) in the liver. In this study, the STZ alone and STZ+DEN treated rats showed significantly elevated levels of ALP, TB and DB in the serum, which is indicative of hepatotoxic damage due to both the inducing agents. The increase in the level of ALP could be due to variation in the membrane permeability of the liver leading to defective transport of metabolites. Further, significant elevation of bilirubin level in the STZ+DEN treated group may be due to leakage of bilirubin into the circulatory system resulting from hepatocellular damage. This leads to the permeability of the liver membrane, altering the build-up of unconjugated bilirubin in the blood, as reported in earlier studies. ${ }^{27,28}$ The two serum protein levels, albumin and globulin, are routinely measured and are recognized as a predictive index in various types of cancer, including liver cancer. ${ }^{29}$ In the present study, administration of STZ+DEN altered the levels of serum albumin and globulin, which is an indication of impairment in the protein biosynthesis of the liver. ${ }^{30}$ The production of ROS decreases the total serum protein content in the STZ+DEN-treated rats. This variation could be resultant of DEN toxification, which causes disruption 
and dissociation of polyribosomes on endoplasmic reticulum (ER) thus reducing the biosynthesis of protein. ${ }^{31,32}$ Treatment with asarone and metformin significantly altered the activities of the above markers in STZ+DEN-induced diabetic-HCC rats. This indicates the maintenance of plasma-membrane stabilizing activity, thus suppressing the release of marker enzymes through membranes and restoration of the proteins synthesis by protecting the polyribosomes, exhibiting hepatoprotective action and inhibiting carcinogenesis.

The SOD and CAT act as scavengers enzyme and preserve the cellular integrity from oxidative mediated stress by maintaining the homeostasis of the biological system. ${ }^{33}$ The SOD particularly scavenges and converts the superoxide anion $\left(\mathrm{O}_{2}^{-}\right)$to oxygen $\left(\mathrm{O}_{2}\right)$ and hydrogen peroxide $\left(\mathrm{H}_{2} \mathrm{O}_{2}\right)$ and CAT, a ubiquitous enzyme consisting iron helps in the formation of water and oxygen by detoxifying hydrogen peroxide. ${ }^{34,35}$ The GPx also plays a role in detoxifying $\mathrm{H}_{2} \mathrm{O}_{2}$ similar to $\mathrm{CAT}^{36}$ The reduced activities of these enzymic antioxidants in diabetic-HCCinduced rats indicate the lack of ability and uncontrolled utilization in deactivating the ROS produced through the chemical modification of STZ+DEN. Further, the status of LPO of unsaturated fatty acids is also taken as straight validation for oxidative related stress as a result of the direct reaction of oxygen and lipids. This, in turn, produces radical intermediates and semi-stable peroxides such as malondialdehyde (MDA). ${ }^{37}$ An elevated level of MDA in the STZ+DEN treated rats indicates enhanced LPO, thereby leading to hepatic injury and failure of the antioxidant defence mechanisms. This increase in the LPO levels is in accordance with earlier reports, as observed in the experimental liver tissues of diabetes or cancer models. ${ }^{38,39}$ However, following oral administration of asarone and metformin, the activities of these enzymatic antioxidants are restored which is an indicator for its ability to scavenge the ROS, thus preventing the further damage from oxidative stress due to STZ+DEN.

The STZ+DEN-induced liver damage and ROSmediated oxidative stress decreased the non-enzymic antioxidants levels, namely the GSH and Vitamin-C. The GSH is mainly involved in inhibiting the oxidative stress and acts against $\mathrm{LPO}^{40}$ Similarly, Vitamin-C, a hydrophilic antioxidant in unification with glutathione removes or deactivates the generated free radicals. ${ }^{41}$ However, following oral administration of asarone and metformin, the levels of these non-enzymatic antioxidants are significantly increased when compared to STZ+DEN group. This elevation to the near-normal level by the test compounds confirms the protection and subsequent prevention form STZ+DEN-mediated oxidative stress.
In confirmation to our experiment, treatment with asarone and metformin to STZ+DEN rats either decreased or altered the severity in hepatocellular damage which is evidenced by the hepatic marker enzymes, antioxidants enzymes and histopathological observation.

In conclusion, reactive oxygen-mediated oxidative stress is predominant in the initiation and growth of hepatocarcinogenesis during the diabetic condition. The administration of asarone and metformin significantly ameliorates the changes in both the hepatic marker enzymes and antioxidant enzymes in diabetic-HCC rats, hence protecting the liver from oxidative stressinduced damage. However, the investigation about the possibility of involvement of the exact mechanism of action through cancer-signalling pathways is essential in controlling the progression of HCC.

\section{ACKNOWLEDGEMENT}

Authors thank the Principal, KLE College of Pharmacy, Hubballi for providing the facilities to carry out the research work.

\section{CONFLICT OF INTEREST}

The authors declare that they have no conflict of interest.

\section{ABBREVIATIONS}

HCC: Hepatocellular carcinoma; STZ: Streptozotocin; DEN: Diethylnitrosamine; ROS: Reactive oxygen species; SOD: Superoxide; CAT: Catalase; LPO: Lipid peroxidation; GPx: Glutathione peroxidase; GSH: Reduced glutathione.

\section{REFERENCES}

1. Cho NH, Shaw JE, Karuranga S, Huang Y, DaRocha FJD, Ohlrogge AW, et al. IDF diabetes atlas: global estimates of diabetes prevalence for 2017 and projections for 2045. Diabetes Res Clin Pract. 2018;(138):271-81.

2. Poitout V, Robertson RP. Glucolipotoxicity: fuel excess and beta-cell dysfunction. Endocr Rev. 2008;29(3):351-66.

3. Davila JA, Morgan RO, Shaib Y, McGlynn KA, El-Serag HB. Diabetes increases the risk of hepatocellular carcinoma in the United States: A population-based case control study. Gut. 2005;54(4):533-9.

4. Wang C, Wang X, Gong G, Ben Q, Qiu W, Chen Y, et al. Increased risk of hepatocellular carcinoma in patients with diabetes mellitus: A systematic review and meta-analysis of cohort studies. Int J Cancer. 2012;130(7):163948.

5. Li S, Tan HY, Wang N, Zhang ZJ, Lao L, Wong CW, et al. The role of oxidative stress and antioxidants in liver diseases. Int J Mol Sci. 2015;16(11):26087124.

6. Matough FA, Budin SB, Hamid ZA, Alwahaibi N, Mohamed J. The role of oxidative stress and antioxidants in diabetic complications. SQU Med J. 2012;12(1):5-18.

7. Roberts CK, Sindhu KK. Oxidative stress and metabolic syndrome. Life Sci. 2009;84(21-22):705-12. 
8. Li M, Li X, Zhang H, Lu YY. Molecular mechanisms of metformin for diabetes and cancer treatment. Front Physiol. 2018;(9):1039.

9. Shankaraiah RC, Callegari E, Guerriero P, Rimessi A, Pinton P, Gramantieri $\mathrm{L}$, et al. Metformin prevents liver tumourigenesis by attenuating fibrosis in a transgenic mouse model of hepatocellular carcinoma. Oncogene. 2019;38(45):7035-45.

10. Zhou G, Myers R, Li Y, Chen Y, Shen X, Fenyk-Melody J, et al. Role of AMPactivated protein kinase in mechanism of metformin action. J Clin Invest. 2001;108(8):1167-74.

11. Das BK, Swamy AHMV, Koti BC, Gadad PC. Experimental evidence for use of Acorus calamus (asarone) for cancer chemoprevention. Heliyon. 2019;5(5):e01585.

12. Liu YX, Si MM, Lu W, Zhang LX, Zhou CX, Deng SL, et al. Effects and molecular mechanisms of the antidiabetic fraction of Acorus calamus $\mathrm{L}$. on GLP-1 expression and secretion in vivo and in vitro. J Ethnopharmacol. 2015;(166):168-75.

13. Sharma V, Sharma R, Gautam DS, Kuca K, Nepovimova E, Martins N. Role of Vacha (Acorus calamus Linn.) in neurological and metabolic disorders: Evidence from ethnopharmacology, phytochemistry, pharmacology and clinical Study. J Clin Med. 2020;9(4):1176.

14. Das BK, Choukimath SM, Gadad PC. Asarone and metformin delays experimentally induced hepatocellular carcinoma in diabetic milieu. Life Sci. 2019;(230):10-8.

15. Kakkar P, Das B, Viswanathan P. A modified spectrophotometric assay of superoxide dismutase. Indian J Biochem Biophys. 1984;21(2):130.

16. Sinha AK. Colorimetric assay of catalase. Analy Biochem. 1972;47(2):389-94.

17. Niehaus WG, Samuelsson B. Formation of malonaldehyde from phospholipid arachidonate during microsomal lipid peroxidation. Eur J Biochem. 1968;6(1):126-30.

18. Jiang ZY, Hunt JV, Wolff SP. Detection of lipid hydroperoxides using the fox method. Anal Biochem. 1992;202(2):384-9.

19. Ohkawa H, Ohishi N, Yagi K. Assay for lipid peroxides in animal tissues by thiobarbituric acid reaction. Anal Biochem. 1979;95(2):351-8.

20. Rotruck JT, Pope AL, Ganther HE, Swanson AB, Hafeman DG, Hoekstra WG. Selenium: Biochemical role as a component of glutathione peroxidase. Science. 1973;179(4073):588-90.

21. Ellman GL. Tissue sulfhydryl groups. Arch Biochem Biophys. 1959;82(1):70-7.

22. Omaye ST, Turnbull JD, Sauberlich HE. Selected methods for the determination of ascorbic acid in animal cells, tissues and fluids. Methods Enzymol. 1979;(62):1-11.

23. Giovannucci E, Harlan DM, Archer MC, Bergenstal RM, Gapstur SM, Habel LA, et al. Diabetes and cancer: A consensus report. CA: Cancer J Clin. 2010;60(4):207-21.

24. Fedirko V, Lukanova A, Bamia C, Trichopolou A, Trepo E, Nothlings U, et al. Glycemic index, glycemic load, dietary carbohydrate and dietary fiber intake and risk of liver and biliary tract cancers in western Europeans. Ann Oncol. 2013;24(2):543-53.

25. Kume E, Fujimura H, Matsuki N, Ito M, Aruga C, Toriumi W, et al. Hepatic changes in the acute phase of streptozotocin (STZ)-induced diabetes in mice. Exp Toxicol Pathol. 2004;55(6):467-80.

26. Pitocco D, Zaccardi F, Stasioet ED, Romitelli F, Santini SA, Zuppi C, et al. Oxidative stress, nitric oxide and diabetes. Rev Diabet Stud. 2010;7(1):15-25.

27. Sallie R, Tredger JM, Williams R. Drugs and the liver. Part 1: Testing liver function. Biopharm Drug Dispos. 1991;12(4):251-9.

28. Ramakrishnan G, Augustine TA, Jagan S, Vinodhkumar R, Devaki T. Effect of silymarin on $\mathrm{N}$-nitrosodiethylamine induced hepatocarcinogenesis in rats. Exp Oncol. 2007;29(1):39-44.

29. Singh D, Singh M, Yadav E, Falls N, Singh DD, Kumar V, et al. Attenuation of diethylnitrosamine (DEN) - induced hepatic cancer in experimental model of Wistar rats by Carissa carandas embedded silver nanoparticles. Biomed Pharmacother. 2018;(108):757-65.

30. Clawson GA. Mechanisms of carbon tetrachloride hepatotoxicity. Pathol Immunopathol Res. 1989;8(2):104-12.

31. Rizk SM, Ibrahim SS. Attenuation of N-nitrosodiethylamine-induced liver carcinogenesis in rats by naturally occurring diallyl sulfide. Afr $\mathrm{J}$ Biochem Res. 2008;2(10):197-205.

32. Premkumari S, Balasubramanian MP. Modulatory effects of Hygrophila auriculata on total proteins and nucleic acids in n-nitrosodiethylamine induced hepatocellular carcinoma in rats. IOSR J Pharm Biol Sci. 2012;3(5):19-22.

33. Sies H. Oxidative stress: Oxidants and antioxidants. Exp Physiol. 1997;82(2):291-5.

34. Fridovich I. Superoxide dismutases. Adv Enzymol. 1986;(58):61-97.

35. Murray RK, Granner DK, Mayes PA, Rodwell VW. Harper's Illustrated Biochemistry. 26 ${ }^{\text {th }}$ ed. The McGraw-Hill Companies Inc. 2003.

36. Bhattacharjee R, Sil PC. The protein fraction of Phyllanthus niruri plays a protective role against acetaminophen induced hepatic disorder via its antioxidant properties. Phytother Res. 2006;20(7):595-601.

37. Khan SM. Protective effect of black tea extract on the levels of lipid peroxidation and antioxidant enzymes in liver of mice with pesticide-induced liver injury. Cell Biochem Funct. 2005;24(4):327-32.

38. Sanchez-Parez Y, Carrasco-Legleu C, Garcia-Cuellar C, Parez-Carreon $\mathrm{J}$, Hernandez-Garcia S, Salcido-Neyoy $\mathrm{M}$, et al. Oxidative stress in carcinogenesis. Correlation between lipid peroxidation and induction of preneoplastic lesion in rat hepatocarcinogenesis. Cancer Lett. 2005;217(1):25-32.

39. Venkateswaran S, Pari L. Antioxidant effect of Phaseolus vulgaris in Streptozotocin-induced diabetic rats. Asia Pac J Clin Nutr. 2002;11(3):206-9.

40. Rice-Evans CA, Burdon RH. Free radical damage and its control. $1^{\text {st }}$ ed. Amsterdam: Elsevier Science. 1994;28(1):25-66.

41. George J. Ascorbic acid concentrations in dimethylnitrosamine-induced hepatic fibrosis in rats. Clin Chim Acta. 2003;335(1-2):39-47.

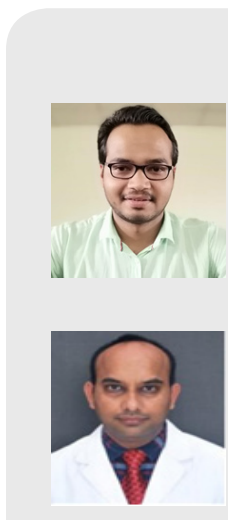

\section{About Authors}

Bhrigu Kumar Das is currently working as a full-time Ph.D. research scholar at KLE College of Pharmacy, Hubballi, Karnataka. His area of interest includes in-vivo and in-vitro models in Pharmacology and Toxicology. Further, his research curiosity also focuses on the molecular pathogenesis of Hepatocellular Carcinoma (HCC).

Dr. Pramod Channabasappa Gadad has obtained his Ph.D. and Post-Doctoral research fellow from the School of Pharmacy and Life Sciences, Robert Gordon University, UK. He has more than eighteen years of teaching experience and currently working as an Associate Professor in the Department of Pharmacology at KLE College of Pharmacy, Hubballi, Karnataka. He also currently holds the position of Project Manager (Off-Campus BSRC of KAHER, Belgaum) in the Cell and Molecular Biology lab. His field of expertise includes diabetes-related complications and metabolic disorders. Further, he is interested in cellular and molecular pharmacology. He is the author of 20 research papers in national and international peer-reviewed journals. 


\section{PICTORIAL ABSTRACT}

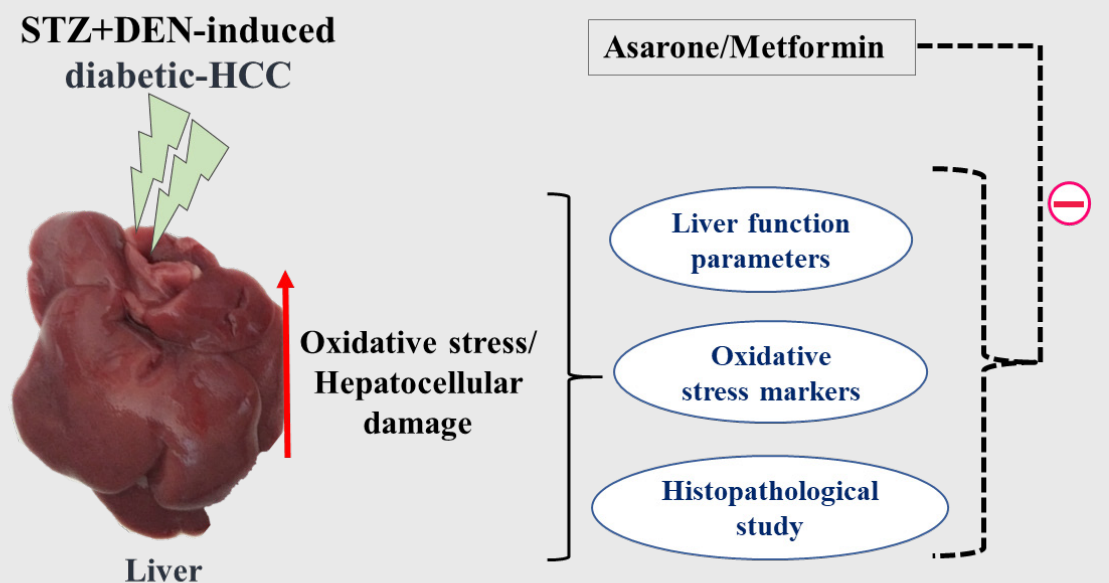

STZ: Streptozotocin; DEN: Diethylnitrosamine; HCC: Hepatocellular carcinoma

\section{SUMMARY}

In the present study, the diabetic-hepatocellular carcinoma (HCC) rats were supplemented with asarone and metformin for 18 weeks. Supplementation of asarone and metformin reduced the burden of streptozotocin (STZ) and diethylnitrosamine (DEN) mediated reactive oxygen species (ROS) and restored the balance of oxidation-antioxidant status along with the liver function parameters. In addition, asarone and metformintreated rats also showed recovery of the hepatic architecture compared to STZ + DEN. Henceforth, asarone and metformin exhibited good hepatoprotective and antioxidant potential against STZ + DEN-induced HCC in rats.

Cite this article: Das BK, Pramod C Gadad. Asarone and Metformin Modulates the Oxidant-Antioxidant Imbalance on Experimentally Induced Hepatocellular Carcinoma during Diabetic Condition. Indian J of Pharmaceutical Education and Research. 2020;54(4):1039-45. 